\title{
Is self-identity essential to objects?
}

\author{
Nicola Spinelli ${ }^{1}$ (D) \\ Received: 11 June 2018 / Accepted: 16 February 2019 / Published online: 1 March 2019 \\ (c) The Author(s) 2019
}

\begin{abstract}
A common view is that self-identity is essential to objects if anything is. Itself a substantive metaphysical view, this is a position of some import in wider debates, particularly (but not exclusively) in connection with such problems as physicalism and personal identity. In this article I challenge the view. I distinguish between two accounts of essence, the modal and the definitional, and argue that self-identity is essential to objects on the former but not on the latter. After laying out my case, I deal with a number of objections.
\end{abstract}

Keywords Identity $\cdot$ Essence $\cdot$ Modality $\cdot$ Definition $\cdot$ Metaphysics

\section{Introduction}

Is self-identity essential to objects? The received view is that if objects have essences at all, self-identity cannot fail to be in them. In their Stanford Encyclopedia of Philosophy (2016) entry "Accidental versus Essential Properties", Teresa Robertson and Philip Atkins characterise minimal essentialism - a position so modest that some even dispute it is a genuine variety of essentialism - as the view that the only essential properties of objects are "trivial" ones, such as "being self-identical". The implication being that if one believes in essence, then that this includes self-identity is the very least one ought to say. The philosophical community, or the part of it that believes in essence, would thus answer my question with a resounding "yes". Yet if I am right, and I will state my position shortly, that answer is mistaken —or, at least, it should be qualified in an important way.

First of all, some definitions. By the essence of an object $x$ I understand a collection of properties $p_{1}, \ldots, p_{n}$ that determine what $x$ is. There are alternative approaches to essence. Aristotle, for example, thought that the essence of primary substances is their individual form (Metaphysics Z6, 1031 ${ }^{b} 18$ ), which, whatever it may be, is

Nicola Spinelli

nicola.spinelli@kcl.ac.uk

1 King's College London, Hertswood Academy, Cowley Hill, Borehamwood WD65LG, UK 
not a collection of properties. The idea that essences are collections of properties is, however, part and parcel of the views I will be concerned with in this paper. ${ }^{1}$ This motivates the assumption.

I also stipulate that properties are neither identical with, nor reducible to, their (possible or actual) instances or extensional constructs based thereupon (e.g., sets of ordered couples $\langle$ instance, $T\rangle$ ). This has the welcome consequence that objects, at least typically, are neither parts nor elements, nor constituents in any sense, of the properties they have, and in particular of the properties they have essentially.

There are at least two ways to hear talk of self-identity. One way is to understand self-identity as the property of being something that is identical to itself: $(\lambda x \cdot x=x){ }^{2}$ Call this general self-identity. Accordingly, an object $a$ is generally self-identical if and only if it instantiates $(\lambda x . x=x)$. The other way to understand self-identity is as the property of being identical to a given object: $(\lambda x . x=a)$, where " $a$ " is a constant (a proper name) ${ }^{3}$ Call this specific self-identity. Accordingly, an object $a$ is specifically self-identical if and only if it instantiates the property of being identical to a fixed object. Notice that while there is only one general self-identity, there are as many specific self-identities as there are objects. Also notice that, for an arbitrary object $a$, there is only one object that is $a$-specifically self-identical, and that object is $a$.

Why does the question whether self-identity is essential to objects have any relevance at all outside the relatively small circle of essentialists? Examples span a number of debates in metaphysics (modality, time, physicalism, personal identity), as well as in logic and the philosophy of language. A couple will do, for general motivation.

Personal identity Specific self-identities are, at bottom, haecceities. These are nonqualitative properties whose role, in the relevant debates, is either to distinguish (identify) qualitatively identical (different) objects, or to identify (distinguish) objects without reference to their qualities. Haecceities are deployed, for example, in some versions of the so-called Simple View: the view that personal identity, or the persistence of personal identity over time, are primitive facts, irreducible to e.g. psychological or physical, bodily facts. ${ }^{4}$ According to those theories, what it is to be identical to an individual $a$ is just to have $a$ 's haecceity, $(\lambda x \cdot x=a)$. Moreover, if to an individual $a$ is associated a haecceity — a specific self-identity — then, no matter how wildly his

\footnotetext{
1 Relations, which may also appear in essences, are here reduced to $\lambda$-abstracted complex properties (more about $\lambda$-abstraction later). This means that instead of speaking of, e.g., Socrates and the Eiffel tower being or not being in the relation of identity, I will speak of Socrates having, or not having, the property of being identical with the tower. While metaphysically this is not neutral, I do not see that it is suspicious-at least for the purpose of this paper. I also do not rule out that essentialist collections of properties (or properties and relations) may be somehow structured.

${ }^{2}$ I will use $\lambda$-notation for property abstraction, although, strictly speaking, it is a device for function abstraction. Given that at the outset I stipulated that properties are not extensional, set-theoretical constructs, the use of $\lambda$-abstraction may seem inappropriate. The only alternative I know of is George Bealer's bracket notation (Bealer 1982 and elsewhere) — which however is rather niche. So I will stick to the more familiar option. Notice, however, that $\lambda$-notation can be used in non-extensional (and indeed hyperintensional) contexts; see for example Fox and Lappin (2005), Menzel (1986, 1993).

3 In principle, a definite description might also be suitable here; but complications would then arise in modal contexts-which are quite important when it comes to essence. That is why I require " $a$ " to be a proper name.

4 The Simple View is minoritarian, but has had some notable endorsers: Chisholm (1969), Madell (1981, 2014), Swinburne (1984), Merricks (1998).
} 
qualitative (physical or psychological) life may vary over a stretch of time, he will still be the individual, and the only one, having the property of being identical to $a$. See for example Baker (2013). Some philosophers in the debate do not think haecceities are genuine properties. Those who do, however, should be interested in the question whether an individual and his haecceity are not only associated, but essentially associated. For, assuming that personal identity depends on haecceities, if the latter is not essential to persons, then plausibly personal identity isn't, either. Which, if one believes in essence, is probably an unwelcome result. Baker, for instance, is aware of this, and does require essentiality.

Physicalism Hofweber (2005) argues that physicalism (the view that the nonphysical supervenes on the physical) is incompatible with the existence of object-dependent properties. In turn, the existence of object-dependent properties is entailed by the semantic thesis of direct reference (the view that the meaning of some or all linguistic items lies in their worldly referent). The incompatibility, then, is between physicalism and direct reference. Both views are widely held, so it is interesting to know whether they conflict. If they do, that is doubly interesting: for physicalism belongs to metaphysics, while direct reference belongs to semantics. Hofweber's argument turns on the following ideas: some properties are object-dependent; some object-dependent properties are "uniqueness" properties (i.e., properties such that at most one thing can have them in each possible world); uniqueness properties cannot supervene on the physical. Assuming that at least some physical objects have uniqueness properties, it follows that at least some objects have properties that cannot supervene on the physical. Uniqueness properties (at least the ones Hofweber is interested in)-and this is where this paper becomes relevant to the debate_-are just specific self-identities. The property of being Clinton- $(\lambda x \cdot x=c)$-is Hofweber's favourite. If one believes in specific self-identities, then, and one is sympathetic with physicalism, one will feel the bite of the argument. Now, Hofweber need not be right; indeed, he has suffered powerful criticisms (Daly and Liggins 2010; Almotohari and Rochford 2011). But suppose he is right (in any case, I would be wary of calling the debate settled). Then the haecceity-friendly physicalist is in trouble and will be looking for a backdrop. Here is one: although not all the properties of an object supervene on its physical properties, all the essential ones do-and those are the ones that really matter. Yet the move is only available to the physicalist if specific self-identities (or other uniqueness properties, if any) are not essential to objects: for otherwise there would be essential properties of objects that physicalism cannot capture. Coupled with Hofweber's argument, then, a "yes" answer to my question may spell trouble for the physicalist.

So much for motivation and wider import. My view is now that different views of essence yield different answers to the question whether self-identity, general or specific, is essential to objects.

In particular, if you hold (a version of) the modal account of essence-according to which a property $p$ is in the essence of an object $x$ if and only if, necessarily, if $x$ exists then $x$ has $p$-then you are committed to answering that yes, self-identity, both general and specific, is essential to objects.

If, on the other hand, you hold a definitional account of essence-according to which essence is a primitive notion, to be understood on the model of real definition- 
then you are committed to answering that no, self-identity, either general or specific, is not essential to objects.

Although it has been on the contemporary philosophical scene for more than twenty years, and is beginning to be included in metaphysics course syllabi, the definitional approach is still less established than its competitor. I will thus allow myself to elaborate briefly on it.

\section{The definitional account of essence}

The definitional account of essence has a pars destruens and a pars construens. The former is an array of arguments against the modal account. The latter is the view, variously formulated, that essence is a primitive concept to be understood on the model of real definition. Most of the pars destruens is due to Kit Fine (1994). ${ }^{5}$ He gives a number of what I shall call symptomatic arguments and an overall diagnostic argument. The latter is a sort of open-question argument intended to generalise the results of its symptomatic counterparts. These, in turn, are meant to produce counterexamples (or families thereof) to the modal account. Due to the nature of my own arguments in this paper, I will concentrate on the symptomatic part of Fine's case and leave diagnosis to one side.

The notion of essence that both the modal and the definitional accounts are meant to capture is "what a thing is" (on an alternative and, I think, somewhat more slippery formulation, "what makes a thing the thing that it is"). If the modal account is correct, then the essence of a thing $x$ is a set of properties that $x$ must have if it exists. The first two counterexamples are fairly well-known. I will frame them in terms of relations as Fine does, but they may easily be recast in terms of corresponding properties according to my initial definition of essence. First, consider Socrates and the set whose sole member is Socrates. Necessarily, Socrates belongs to singleton Socrates if he exists: for if Socrates exists then the singleton does, and if both exist then the former belongs to the latter. Thus, according to the modal account, Socrates essentially belongs to singleton Socrates. Yet, intuitively, belonging to singleton Socrates is not part of what Socrates is (which is the target notion of essence). The second counterexample features a concrete rather than an abstract object. Take Socrates and the Eiffel Tower. Necessarily, Socrates and the tower are distinct (if they exist). Thus, on the modal account being distinct from the tower is part of Socrates' essence. Yet intuitively that is not so.

In general, there seems to be a difference between saying that belonging to singleton Socrates is part of what Socrates is, and saying that having Socrates as a member is part of what singleton Socrates is. The difference is that while the second essentialist claim is probably uncontroversial, the first is at least debatable. However, no corresponding modal asymmetry can be made out: for it is just as necessary that Socrates should belong to singleton Socrates (if he exists) as it is necessary that singleton Socrates should have Socrates as its sole member. Thus, Fine reasons, for an object to have a

\footnotetext{
5 Lowe (2008), Hale (1996) and Mulligan (2004) all offer additional arguments against the modal account of essence. Earlier versions of some of the arguments in Fine (1994) may be found in Dunn (1990).
} 
property essentially is not simply for it to have it necessarily: because if it were, then there would be a modal asymmetry corresponding to the essentialist one-which is not the case.

The modal account has yet other problems, which have to do with the logical form of de re essentialist attributions. I will mention three. First, take any necessary truth-a mathematical truth, for example, or the proposition that if the moon is made of cheese then the moon is made of cheese. A conditional whose consequent is a necessary truth is itself necessary. Thus, necessarily, if Socrates exists he is such that, say, there is a bijection between the primes and the naturals, or such that if the moon is made of cheese then the moon is made of cheese. But surely these properties are not part of what Socrates is.

Furthermore, if the modal account is correct, essentialist truths are among the necessary ones. Now, accept for example that the Eiffel Tower is essentially a material object. Then the Eiffel Tower will also be a material object necessarily. As a consequence, however, on the modal account the following truth: "Necessarily, if Socrates exists then he is such that the Eiffel Tower is essentially a material object" will state the essence of Socrates - and so will any conditional whose antecedent is "Socrates exists" and whose consequent is "Socrates is such that $\phi$ ", where $\phi$ is an essentialist (a necessary) truth about anything whatsoever.

Finally, every proposition necessarily implies itself. Hence, necessarily, if Socrates exists then Socrates exists. Thus, on the modal account it is part of the essence of Socrates (in fact, of every thing) that he (it) should exist. There are two problems with this, one more obvious than the other. The obvious problem is that very few people would be happy to accept that everything essentially exists. Not simply because very few people would be happy to accept that everything necessarily exists, but also because it is unclear that existence should be part of what a thing is: intuitively, once I know that the ten-pound note I have in my pocket exists, I know nothing more about its nature. This, notice, is not necessarily to say, with Kant, that existence is not a real predicate; rather, even if existence, pace Kant, is a real predicate, it is not part of what things are, of their essence. The not-so-obvious problem is that even if we accepted that it is part of the essence of every thing that it should exist, in this connection that would not be true in virtue of what each and every thing is, or even in virtue of what it is to be a thing, but in virtue of what essence is according to the modal account. Substantive questions of essence, that is, would be settled by definition-not, notice, the definition of the things involved, but the definition of the concept of essence. Which looks like an undesirable outcome.

Though not without its critics (Della Rocca 1996; Gorman 2005; Zalta 2006; Correia 2007; Cowling 2013; Chaoan 2016; Wildman 2016 to name a few), overall Fine's case against the modal account seems strong enough to motivate a search for alternative views. One such view is what I call the Definitional account of essence, pars construens. According to it, essence is a primitive concept to be modelled on real definition. Thus, although no definition or analysis of essence in terms of real definition is attempted, for the Definitionalist the following biconditional is true (quantification is suppressed for readability): 
(1) Property $p$ is in the essence of object $x$ if and only if $p$ appears in a complete or partial real definition of $x$.

This gives us at least a test for definitional essentiality: if property $p$ is no part of any (complete or incomplete) real definition of $x$, then-by (1)-it is not in the essence of $x$.

Notice that no definition or analysis of real definition is proposed. This will not be welcome to some, for the notion of real definition itself is not entirely unexceptionable. In an influential book, R. Robinson is very sceptical as to the usefulness on the concept: "Real definition flourishes because the question-form 'What is $x$ ?' flourishes; and this question-form flourishes precisely because it is vague. It saves us the trouble of thinking out and saying exactly what it is that we want to know about $x$ " (Robinson 1950). Even though, I think, this sort of stance is not genuinely threatening for purveyors of real definition, it does raise a worry. Another worry, highlighted by Robertson and Atkins, is that not all kinds of objects may be equally really-definable: properties and relations probably are, but what about particulars (such as Socrates) $?^{6}$ Be this as it may, it seems that Definitional Essentialists are simply committed to thinking that particulars admit of real definition - unless they are prepared to say that particulars have no essence.

The Definitional essentialist also holds (semi-formally, and again suppressing quantification, for readability):

(2) It is not the case that: (Necessarily, if $x$ exists $x$ has $p) \rightarrow(p$ is in the essence of $x$ ).

That is to say, necessity is not a sufficient condition for essentiality. This is just what the failure of the modal account amounts to. Finally, many prominent Definitional essentialists, including Fine, Hale and Lowe, believe that necessity, although it is not a sufficient condition for essentiality, is a necessary one:

(3) If $p$ is in the essence of $x$, then, necessarily, if $x$ exists it has $p$.

Notice, however, that (1) and (2) do not entail (3). Thus, at least on the face of it, one can be a Definitional essentialist and think that essence is contingent. I will come back to this later on.

\section{Is self-identity essential to objects?}

My view, to state it again, is that if you are a Modalist you should answer the question in the positive, while if you are a Definitionalist you should answer it in the negative.

As far as the modal account goes, the argument is simple. General self-identity. Surely, for every object $x$, it is necessarily the case that if $x$ exists it instantiates the property of being identical to $x,(\lambda x \cdot x=x)$. To coin a phrase, no entity without identity. But then that property is in the essence of every object. Specific self-identity. Surely it is necessarily the case that an arbitrary but given object $a$, if it exists, instanti-

\footnotetext{
6 Attempts at tacking — in fact, at defining - real definition for properties and relations are Rosen (2015) and Correia (2017). Interestingly, Correia's view (2006, 2017) is that defining an object is defining its specific self-identity. A "no" answer to my question would be a problem for that theory.
} 
ates the property of being identical with $a,(\lambda x \cdot x=a)$. But then specific self-identity is in the essence of every object.

The picture changes completely if we switch to the definitional account of essence. Here the modal facts above, robust as they may be, are immaterial: because on the definitional account_recall (2)—necessity is (perhaps a necessary, but) not a sufficient condition for essentiality: essentiality does not follow from necessity. It can thus very well be the case that objects are necessarily self-identical both generally and specifically, and yet self-identity, either general or specific, fails to be in their essence. Unless, that is, it can be shown that self-identity is also in the definition of objects: that would give rise to a strong "yes" case.

Before I move on, I should mention that most of the critics of Definitional Essentialism, while remaining Modalists, accept that Fine's arguments are fatal to an unqualified form of Modalism. In other words, they believe we should be Modalists, but in a qualified way. Now, at least some varieties of qualified or new Modalism may yield different results than unqualified Modalism about self-identity. On Zalta's view, for example, the latter is "weakly essential" but not "strongly essential" to (ordinary) objects. It is therefore possible that the new Modalist should be more hawkish on the issue of self-identity than the old one. Since I have no space to investigate the possibility, not least because new Modalisms are several and varied, readers should be aware that in the remainder of this paper by "Modalism" I will understand "old or unqualified Modalism". 7

\subsection{The argument from relevance}

Is self-identity-either general or specific - in the definition of objects? Intuitions seem to speak in favour of deniers. It would be odd, for example, to (partially) define Socrates as a self-identical male human. Similarly, it would be odd to define number 2 as the self-identical successor of 1 -or as the self-identical set $\{\emptyset,\{\emptyset\}\}$. Examples can be multiplied. In all cases there is a clear feeling that something is amiss. The feeling can be made more precise by breaking the overall information given by a (complete or incomplete) real definition into bits corresponding to individual properties, and by checking whether these bits are relevant to answering the question as to what the definiendum is. The properties of being human and male are clearly relevant to specifying what Socrates is. So is the property of being the successor of 1 in the case of number 2. Is the information that Socrates (number 2) is self-identical relevant to specifying what Socrates (number 2) is? I would say no: once we know that Socrates (number 2) is self-identical we don't know the first thing about what he (it) is. The same is true of the information that Socrates (number 2) is identical to Socrates (number 2).

I wish to stress that for Definitional essentialists considerations of relevance must be factored in-actually, they must be paramount. That is what the whole project stands on: if relevance goes, so does the entire case against the modal account as well as the trademark fine-grainedness of the Definitional approach. There is, of course, a worry associated with this. Some ways of cashing out relevance border, or overlap, with branches of linguistics such as conversational and discourse pragmatics. This will

\footnotetext{
7 Morvarid (2018) features a discussion of new Modalisms and logical properties such as self-identity.
} 
not be welcome to the adamant metaphysician, who is sometimes only just tolerant of having to deal in semantics. The reason is that relevance, pragmatically understood, is context-dependent; and if relevance determines essence at least to an extent, then to that extent essence will also be context-dependent.

Now, if the only route to relevance is pragmatic, then as far as I can see the metaphysician faces a choice: either compromise as to the nature of his enterprise or discard Definitional essentialism. Yet there seems to be a sense of relevance that is not pragmatic to begin with, and which, to that extent, does not make essence contextdependent.

To see this, consider the following valid inferences:

The moon is made of cheese.

Therefore, there are infinitely many primes.

There are infinitely many primes.

Therefore, the cardinality of $\mathcal{P}(M)$, a set $M$ 's power set, is strictly greater than the cardinality of $M$. (Cantor $)^{8}$

Surely there is a sense of relevance according to which in both inferences the conclusion is semantically and context-independently irrelevant to the premise. The same seems to be true of the following (also valid) inference:

Socrates exists.

Therefore, the Eiffel tower is a material object.

I submit that it is the very same sense of relevance whereby in (true) conditionals like:

$$
\begin{aligned}
& \text { Socrates exists } \rightarrow \text { there are infinitely many primes } \\
& \text { Socrates exists } \rightarrow \text { Socrates is distinct from the Eiffel tower }
\end{aligned}
$$

the consequent is said to be irrelevant to the antecedent—which is what grounds Fine's claim that such conditionals do not express the essence of Socrates. Notice that, while appeal to inferences and conditionals is useful to make the point, it is by no means compulsory. Surely there is a sense of relevance whereby the property of being a prime number is relevant to the sentence There are infinitely many primes and irrelevant to the sentence Socrates exists. And it is hard to see how relevance is here context-dependent. Notice that this notion of relevance is the basic motivation for relevance logics, and does some work in other systems too (Dunn and Restall 2002). It is also crucial to fine-grained intensional logics and semantics (see Fox and Lappin 2005; Jespersen and Duži 2015, for good overviews of the field). If all this is correct, then probably the adamant metaphysician need not worry about relevance more than he should worry about semantics.

Before I move on, let me finesse the argument from relevance a little more. Deictic contexts may blur intuitions in the case of specific self-identity. Surely, one could say, there is a sense in which the information that that object (a demonstrated entity rather

\footnotetext{
8 If the conclusions are taken to be logical truths (which depends on your philosophy of mathematics), the inferences will also be classically valid.
} 
than a specified one) has $(\lambda x \cdot x=a)$ is relevant to what that object is. If that is so, then it appears that specific self-identity could be essential to objects. Yet, I think, appearances deceive. Suppose we know what a certain object $a$ is-i.e., we know its essence: properties $x y z$. Also suppose that, upon seeing that object we do not recognise it as $a$. Suppose somebody tells us that that object has property $(\lambda x \cdot x=a)$. Presumably, we will then take it (and rightly so) that the essence of that object is just the essence of $a$. And since we know what $a$ is (i.e., $x y z$ ), in the end we will know the essence of that object, too. The question is: is $(\lambda x \cdot x=a)$ in that essence? Notice that if - owing to the fact that that object has $(\lambda x \cdot x=a)$-that object and $a$ have the same essence, then that object has $(\lambda x \cdot x=a)$ essentially only if (it has $(\lambda x \cdot x=a)$ and) $a$ has $(\lambda x \cdot x=a)$ essentially. And this is how it should be: because, while thanks to the information that that object has $(\lambda x . x=a)$ our knowledge of that object has changed, the object has stayed the same: it would be absurd to claim that its essence has gained a property — specific self-identity — in virtue of the object's having been referred to with a deictic expression. In general, since essences do not change from non-deictic to deictic contexts, specific self-identity is essential to objects in the latter case only if it is in the former. Now, since intuition and the argument from relevance suggest (strongly, or so I believe) that in non-deictic contexts specific self-identity is not essential to objects, then by considerations of uniformity we should extend our conclusion to deictic contexts, too-even if intuitions about them are blurred.

\subsection{The argument from circularity}

The argument from relevance applies to both the general and the specific sense of self-identity. In the latter case, however, there is a further complication: a definition of object $a$ that includes a clause such as "is identical to $a$ ", or indeed anything that refers back to $a$, is bound to be circular, as the definiens would then include the definiendum. Call this the argument from circularity. Although it leaves the case against general self-identity untouched, it seems to strengthen that against specific self-identity. ${ }^{9}$ Yet, a few remarks are in order.

In an article, Fine explores the possibility that what he calls "self-related" and "reflexive" properties may be in the essence of objects. A property of an object is self-related if it involves the object itself-e.g., specific self-identity. A property of an object is reflexive if it involves the object in "a reflexive as opposed to a direct" way (Fine 1995) - e.g., general self-identity. To every self-related property corresponds a reflexive property. Fine is interested in the connection between the essential possession of properties of the two kinds. While working on that, he seems to acknowledge that allowing self-related properties in the essence of objects leads to circularity. However, he also appears to think that allowing both a self-related and the corresponding reflexive property avoids circularity: for, he writes, "the reflexive properties can be attributed to the essence on the basis of their reflexive counterparts (sic)". As it is, this does not seem to make much sense. There probably is a typo and we should substitute self-related for one of the two occurrences of reflexive. But which one? I should say the first. The sentence would then read: "The self-related properties can be attributed

\footnotetext{
9 It is worth noting that all the debates mentioned in Sect. 1 feature specific rather than general self-identity.
} 
to the essence on the basis of their reflexive counterparts". Circularity would then be avoided because, while the self-related property is in the essence of the object, it is because the corresponding reflexive property is. ${ }^{10}$

To see how this may work, we need to bring in a further distinction Fine makes in the same article: that between constitutive and consequential essence. A property is in the constitutive essence of an object if it is not a logical consequence of any other property essential to the object. ${ }^{11}$ Otherwise, the property is in the consequential essence of the object. The claim that a self-related property may be in the essence of an object on the basis of the corresponding reflexive property's being in that essence should then, perhaps, be understood in terms of constitutive and consequential essence-as follows. The reflexive property may be in the constitutive or in the consequential essence of the object; we can be agnostic here. But whichever it is, the corresponding self-related property will only be in the consequential essence, because its being essential to the object in the first place is a logical consequence of its reflexive counterpart's being essential to the object.

To what extent is this view a threat to the argument from circularity? As far as I can see, it is no threat at all. Fine (or rather Fine as I am reading him) may well be right, but the fact remains that a self-related property cannot be in the definition of an object, on pain of circularity. Thus, if the property is in the consequential essence of the object - to which I am not objecting-it must follow that consequential essence cannot be understood simply in terms of definition. This is something Fine would probably agree with: consequential essence should be understood in terms of definition and logical consequence. For this very reason, though, the notion of consequential essence is not something the Definitional essentialist must accept. I myself find it artificial — and, more to the point, with little basis in the original idea of understanding the elusive concept of essence in terms of the (perhaps only slightly) less elusive concept of real definition: I see nothing in the latter that necessitates an extension in the consequentialist direction. But even if consequential essence is genuine, I would regard it as a result of some significance to have established that if the Definitional essentialist wants to allow specific self-identity in the essence of objects, he must think of definition in a broader and rather unorthodox way-as well as, notice, successfully countering the argument from relevance: for otherwise general self-identity, which is the needed reflexive property, will not be essential to the object, and the whole attempt will still fail.

A final remark concerns the legitimacy of circular definitions. Although they are traditionally banned, between the late 1980s and the early 1990s a General Theory of Definitions was developed which accommodates them (Gupta 1989; Belnap and Gupta 1993). Clearly, if circular definitions turn out not to be problematic, the argument from circularity collapses - though, importantly, the argument from relevance, which unlike the former applies to both general and specific self-identity, is left untouched. Now, for one thing, it would be a rather important result to have shown that one can only be a Definitional Essentialist and accept that specific self-identity is in the

\footnotetext{
${ }^{10}$ I should mention that even though this is the only plausible reading I can give the sentence, it seems to flatly contradict a subsequent passage. So I may be reading it wrong, after all.

11 Property $q$ is a logical consequence of properties $p_{1}, p_{2}, \ldots, p_{n}$ if and only if it is a logical truth, for any object, that if the object has $p_{1}, p_{2}, \ldots, p_{n}$ then it has $q$.
} 
essence of objects if (one successfully counters the argument from relevance and) one buys into the General Theory of Definitions. Second, the Theory concerns definition understood as the fixing of the meaning of the definiendum by giving its possible extensions as a function of the possible extensions of the (terms in the) definiens. But in the context of Definitional Essentialism it is not obvious that that is the right way of thinking of definition. Indeed, the arguments against the modal account of essence suggest, if not entail, that in Definitional Essentialism definition should be understood in a more fine-grained sense. Finally, it seems to me that the Theory only applies to stipulative definitions, which are, at least traditionally, a type of nominal rather than real definition.

\section{Objections and rejoinders}

In this section I discuss a number of objections. While some are more threatening than others, all are worth considering. If I am right, none of them is fatal.

\subsection{Explanatory power}

Most Definitionalists, in addition to (1) and (2), and perhaps (3), also hold:

(4) For every necessary proposition $\square \alpha$, there is an essentialist truth $\beta$ such that $\square \alpha$ because $\beta$.

where an essentialist truth is a true proposition that spells out the essence of some object (or objects collectively taken-I will say something about this option below). ${ }^{12}$ In other words, most Definitionalists believe that essence accounts for, or explains, necessity. Now, given that, necessarily, every object is self-identical, for the Definitionalist that must be so in virtue of some essence (this follows from (4)). A natural candidate is the essence of the object. And it is just as natural, as well as economical, to think that it is the essentiality of self-identity that explains its necessity. It follows that self-identity must be in the essence, and - contrary to appearances - in the definition, of the object.

Notice, for one thing, that the conjunction of (1) and (2) - the core of Definitionalism -does not entail (4). Nor do things change if (3) is allowed in. In other words, strictly speaking a Definitionalist is one who rejects the modal account of essence and who believes that essence is a primitive notion to be understood, if not defined, on the model of real definition. He thus need only endorse some case against the modal account (e.g., Fine's) as well as (1) and (2). (3) is a further commitment on the relations between essence and necessity: it says that every essentialist truth is also necessary. To endorse (4), however, is is to take an even further step. One can thus very well hold (1) and (2), and even (3), and still reject (4). Notice that this is not just a question of nomenclature- the point is not how I define "Definitionalist" (as accepting or not (4) along with (1)-(2) or (1)-(3)) and whether my definition is too restrictive. My own arguments throughout the paper do not rely on the assumption that Definitionalism

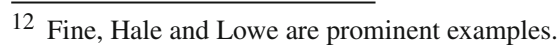


includes (4) (or even (3)). Thus, regardless of whether my nomenclature is strict or loose, the objection is off target.

It is true, however, that most Definitionalists believe that every necessary truth admits of, and in fact requires, an essentialist explanation. It would thus be wrong to simply dismiss the problem. Let me then further discuss it. In fact, let me strengthen the objector's case. Not only is the Definitional Essentialist endorsing (4) committed to explaining, and in essentialist terms, the necessary self-identity of every object. He must also explain, and in essentialist terms, the necessary distinctness of objects that are qualitatively identical. Consider, for example, a possible world with only two distinct but qualitatively identical objects in it, perhaps two equiradial iron spheres at the same physical and chemical conditions. ${ }^{13}$ Presumably, if distinct, they will be necessarily distinct. Yet there seems to be nothing in their essence to account for this except, if allowed in, specific self-identity. But then, so the reasoning goes, if the Definitionalist is to explain their being necessarily distinct in terms of their essence, he will have no choice but to open the essentialist door to specific self-identity.

In both cases, the assumption is that the Definitionalist's explanation should turn on the essence of the objects involved. I will thus propose two alternative explanations that - I believe - are just as plausible and which, however, appeal to the essence of something else. The commitment to (4) will thus be honoured without any concessions to specific self-identity. ${ }^{14}$

Let us first of all look at how the objector's explanations may run in detail. For the necessary-self-identity case we have something like this:

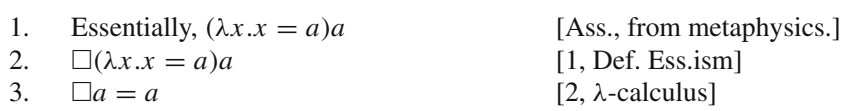

The use of $\lambda$-calculus in essentialist contexts is somewhat loose (to my knowledge it has never been properly regimented), but here I am just trying to make sense of the objection. In the necessary-distinctness-of-qualitatively-identical-objects case we have: ${ }^{15}$

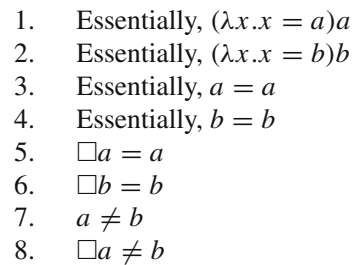
[Metaphysics]
[Metaphysics]
$[1, \lambda$-calculus $]$
$[2, \lambda$-calculus $]$
[3, Def. Ess.ism]
[4, Def. Ess.ism]
[Metaphysics]
$[5,6,7$, logic $]$

Notice that the assumption that $a \neq b$ (step 5) seems needed for the inference to go through. It is not essentialist, as being distinct from $a$ (from $b$ ) is not in the essence of $b$ (or of $a$ ), at least typically. It is conceivable that the relational property $(\lambda x y \cdot x \neq y$ ) should be in the essence of the pair $a, b$ (collective essence); but this would defeat

\footnotetext{
13 The scenario is Black's (1952), but I am indebted to David Papineau for bringing it to my attention in this connection.

14 I do not claim that mine are the only two alternative explanations. We could appeal to the nature of identity, for example, or go down the collective essence route (we will see some of the latter). The more alternatives, of course, the better for my case.

15 I am indebted to Julien Dutant for helping work out the details.
} 
plausible than the objector's explanation. Crucially, if it is adopted by the Definitional Essentialist then he will be in a position to maintain that self-identity is not essential to objects while retaining full explanatory power with respect to modality.

\subsection{Truth-in-virtue-of}

Definitional Essentialist discourse is sometimes couched in terms of truth in virtue of essence. For example, instead of saying that humanity is in Socrates' essence, we may say that it is true in virtue of Socrates' essence that Socrates is human. Insisting on this kind of wording, one could argue as follows. While

$$
a \text { has }(\lambda x \cdot x=x)
$$

is clearly not true in virtue of what $a$ is, it would (or might) seem that

$$
a \text { has }(\lambda x \cdot x=a)
$$

is true in virtue of what $a$ is. Hence, $(\lambda x \cdot x=a)$ should be in the essence of $a$.

Yet is " $a$ has $(\lambda x \cdot x=a)$ " really true in virtue of what $a$ is? I will now argue that it is not. To set up the argument, I will let "what $a$ is" denote the essence of a minus $(\lambda x . x=a)$. The reason is clear: since we are trying to decide whether the property is in the essence of $a$, if we took "what $a$ is" to denote such essence including $(\lambda x \cdot x=a)$ we would effectively be begging the question (or defining it away).

Notice now, for one thing, that on the face of it one need not know what $a$ is to accept (or believe or even know) that $a$ has $(\lambda x . x=a)$-i.e., that $a$ is the same thing as $a$. While this is by no means conclusive, it does suggest that " $a$ has $(\lambda x \cdot x=a)$ ", though it is true and in fact necessarily so, may not be true in virtue of what $a$ is. That is both interesting in itself and relevant to a point I will be making in a minute. Second, suppose that " $a$ has $(\lambda x \cdot x=a)$ " were true in virtue of what $a$ is-where, again, "what $a$ is" denotes the essence of $a$ minus $(\lambda x . x=a)$. How would this in virtue of relation be cashed out? One option is to do so in logical terms. Thus, on premises (1) that $a$ has properties $u, v, z$ essentially (which make up what $a$ is), (2) that essence individuates, and (3) that anything that has those same properties essentially is identical to $a$ (Identity of Indiscernibles), it follows that $a$ has $(\lambda x \cdot x=a)$. Yet, for one thing, it is not obvious that essence individuates. Second, this line of reasoning, even if successful, would put $(\lambda x \cdot x=a)$ in $a$ 's consequential, rather than constitutive, essence.

Another option to cash out the in virtue of relation is in terms of grounding. This, I conjecture, is the option that most Definitional Essentialists would go for. ${ }^{16}$ Yet grounding is a hyperintensional notion. In particular, grounds must be relevant to groundees. But, recall the point made above, it is not clear that what $a$ is $-a$ 's essence minus $(\lambda x \cdot x=a)$-is relevant to $a$ 's having $(\lambda x \cdot x=a)$ : so much so that there seems to be nothing wrong in accepting that $a=a$ without even trying to gather information as to what $a$ is. Therefore, I submit, one way or another the objection does not go through. ${ }^{17}$

\footnotetext{
16 Fine's most recent view is that essence and grounding have "unified foundations". See Fine (2015).

17 At one point Fine suggests we should treat it is true in virtue of the essence of ... that ... as a primitive and unanalysed operator. This would indeed cut the discussion short: there would be no need to cash out
} 


\subsection{Entities without identity}

The third objection is a variation on the deictic case. It concerns general rather than specific self-identity. Suppose the essence in point is the essence not of that object but of that. The difference is that in the latter case we do not know whether that is an object. Now if, as some have maintained, self-identity is a sufficient condition for objecthood, the information that that is self-identical will indeed be relevant to specifying what that is: because it will follow logically from it that that is an object. Hence, $(\lambda x \cdot x=x)$ should be in the essence of that.

Notice, for one thing, that the objection is strongly dependent on one's view of the relations between self-identity and objecthood. It is true that some philosophers, e.g. Frege, have thought that it is only objects-as opposed to functions-that are self-identical. Yet it is not clear that the position is tenable. It is, after all, in the eye of the "paradox of the concept Horse" storm. And it does entail giving up on identifying properties, relations and propositions especially (though perhaps not exclusively) in a fine-grained way - something that intensional logicians have proved both needless and pointless. But if it is not clear that self-identity is a sufficient condition for objecthood, then it is dubious that the objection gets off the ground.

But assume, for the sake of argument, that we buy into something like Frege's view. Suppose we are discussing that, and suppose we know that if an item has $(\lambda x . x=x)$ then it is an object. Presumably, if we come to know that that has the property we will make the inference and take it that that is an object. But surely, so the reasoning goes, if something is an object it is so essentially; therefore, having $(\lambda x . x=x)$ is relevant to what that is. It will thus also be essential to that.

One question is whether objecthood should be in the constitutive or the consequential essence of that. If it is essential to that because it is a logical consequence of $(\lambda x . x=x)$ 's being essential to that (as generic self-identity's sufficiency for objecthood perhaps suggests), then it is in the consequential essence. But then we would need independent grounds to allow $(\lambda x \cdot x=x)$ in the constitutive essence in the first place. Which was the original problem. If objecthood is in the constitutive essence of that, then the original line against the deictic-case objection kicks in: objecthood was always essential to that, and the inference from general self-identity is just a matter of discovery.

\subsection{Reductio}

Finally, one might say, with somewhat Quinean irony, that the fact that the definitional account does not allow self-identity in the essence of objects is in fact a reductio ad absurdum of the account. For self-identity just is in the essence of objects if anything is. Yet this is either question-begging or claimed with reason. In the first case, I need not worry. As for the second case, it is worth noticing that the view I defended in this

Footnote 17 continued

either essence or the in-virtue-of relation in any way. Yet it seems to me that while formally the option is viable, metaphysically it is just about as suspicious as it gets: it is not clear at all how understanding essence in terms of the unanalysed operator would make the intuitive notion any more intelligible. 
paper is that if one is a Definitional essentialist, then one should not take self-identity to be essential to objects. If my result is sound, then it may indeed be used to argue against Definitional essentialism along the lines of a (possibly rather weak) reductio. I will, however, let Definitional essentialists worry about it.

Acknowledgements I first conceived of this paper in June 2016 during a discussion at the Dorothy Edgington Lectures, Birkbeck college (London). Participants to the discussion were, among others, Stephen Duxbury, Jennifer Hornsby, Antonella Mallozzi, David Papineau. I am grateful to them for not agreeing with me. I am also grateful to Kit Fine for his comments on the same occasion. Finally, I am indebted to my audience at the KCL staff seminar (among others, Bill Brewer, Julien Dutant, Christopher Hughes, David Papineau, Matt Soteriou), as well as to Ivan Ivanov, Guy Longworth, Michi Wallner, and three anonymous reviewers for many helpful observations.

Open Access This article is distributed under the terms of the Creative Commons Attribution 4.0 International License (http://creativecommons.org/licenses/by/4.0/), which permits unrestricted use, distribution, and reproduction in any medium, provided you give appropriate credit to the original author(s) and the source, provide a link to the Creative Commons license, and indicate if changes were made.

\section{References}

Almotohari, M., \& Rochford, D. (2011). Is direct reference theory incompatible with physicalism? The Journal of Philosophy, 108(5), 255-268.

Baker, L. R. (2013). Naturalism and the first-person perspective. Oxford: OUP.

Bealer, G. (1982). Quality and concept. Oxford: OUP.

Belnap, N., \& Gupta, A. (1993). The revision theory of truth. Cambridge, MA: The MIT Press.

Black, M. (1952). The identity of indiscernibles. Mind, 61(242), 152-164.

Chaoan, H. E. (2016). What is not so fine with Fine's critique of the modal account of essence. Frontiers of Philosophy in China, 11(2), 250-262.

Chisholm, R. (1969). The loose and popular and the strict and philosophical senses of identity. In N. Care, \& R. Grimm (Eds.), Perception and personal identity (pp. 82-106). Cleveland: Press of Case Western Reserve University.

Correia, F. (2006). Generic essence, objectual essence, and modality. Nous, 40(4), 753-767.

Correia, F. (2007). (Finean) Essence and (Priorean) modality. Dialectica, 61(1), 63-84.

Correia, F. (2017). Real definitions. Philosophical Issues, 27, 52-73.

Cowling, S. (2013). The modal view of essence. Canadian Journal of Philosophy, 43, 248-266.

Daly, C., \& Liggins, D. (2010). Do Object-Dependent Properties Threaten Physicalism? Journal of Philosophy, 107(11), 610-614.

Della Rocca, M. (1996). Essentialists and essentialism. Journal of Philosophy, 93(4), 186-202.

Dunn, J. M. (1990). Relevant predication 3: Essential properties. In J. M. Dunn \& A. Gupta (Eds.), Truth or consequences: Essays in honor of Nuel Belnap (pp. 77-95). Dodrecht: Springer.

Dunn, J. M., \& Restall, G. (2002). Relevance logics. In D. M. Gabbay (Ed.), Handbook of philosophical logic (Vol. 6). Dodrecht: Springer.

Fine, K. (1994). Essence and modality. Philosophical Perspectives, 8, 1-16.

Fine, K. (1995). Senses of essence. In W. Sinnott-Armstrong, et al. (Eds.), Modality, morality and belief. essays in honor of Ruth Barcan Marcus. Cambridge: CUP.

Fine, K. (2015). Unified foundations for essence and ground. Journal of the American Philosophical Association, 1(2), 296-311.

Fox, C., \& Lappin, S. (2005). Foundations of intensional semantics. Oxford: Blackwell.

Gorman, M. (2005). The essential and the accidental. Ratio, 18(3), 276-289.

Gupta, A. (1989). Remarks on definitions and the concept of truth. Proceedings of the Aristotelian Society, $89,227-246$.

Hale, B. (1996). Absolute necessities. Philosophical Perspectives, 16, 299-319.

Hofweber, T. (2005). Supervenience and Object-Dependent Properties. Journal of Philosophy, 102(1), 5-32.

Jespersen, B., \& Duži, M. (2015). Introduction. Synthese, 192(3), 525-534. 
Lowe, E. J. (2008). Two notions of being: Entity and essence. Philosophy, 83, 23-48.

Madell, G. (1981). The identity of the self. Edinburgh: Edinburgh University Press.

Madell, G. (2014). The essence of the self: In defense of the simple view of personal identity. London: Routledge.

Menzel, C. (1986). A complete type-free 'Second-Order' logic and its philosophical foundations. Stanford: Stanford University, Center for the Study of Language and Information, Report No CSLI-86-40.

Menzel, C. (1993). The proper treatment of predication in fine-grained intensional logic. Philosophical Perspectives, 7, 61-87.

Merricks, T. (1998). There are no criteria of identity over time. Nous, 32(1), 106-124.

Morvarid, H. (2018). Essence and logical properties. Philosophical Studies, pp. 1-21.

Mulligan, K. (2004). Essence and modality: The quintessence of Husserl's theory. In M. Siebel, \& M. Textor (Eds.), Semantik und Ontologie. Beiträge zur philosophischen Forschung. Frankfurt: Ontos Verlag.

Robertson, T., \& Atkins, P. (2016). Essential versus accidental properties. In E. N. Zalta (Ed.), The stanford encyclopedia of philosophy (Summer 2016 Edition). https://plato.stanford.edu/archives/sum2016/ entries/essential-accidental/.

Rosen, G. (2015). Real definition. Analytic Philosophy, 56(3), 189-209.

Spinelli, N. (2016). Husserlian essentialism revisited: A study of essence, necessity and predication. Coventry: University of Warwick.

Swinburne, R. (1984). Personal identity: The dualist theory. In R. Swinburne \& S. Shoemaker (Eds.), Personal identity (pp. 1-66). Oxford: Blackwell.

Wildman, N. (2016). How (not) to be a modalist about essence. In M. Jago (Ed.), Reality making. Oxford: OUP.

Zalta, E. (2006). Essence and modality. Mind, 115(459), 659-694.

Publisher's Note Springer Nature remains neutral with regard to jurisdictional claims in published maps and institutional affiliations. 